\title{
An Adult case of a huge tongue base mucocele
}

Takeshi Kusunoki $^{* 1}$, Hirotomo Homma ${ }^{1}$, Yoshinobu Kidokoro ${ }^{1}$, Aya Yanai $^{1}$, Ryo Wada ${ }^{2}$ and Katsuhisa Ikeda ${ }^{3}$

${ }^{1}$ Department of Otorhinolaryngology, Juntendo University of Medicine, Shizuoka Hospital, Japan

${ }^{2}$ Department of Pathology, Juntendo University of Medicine, Shizuoka Hospital, Japan

${ }^{3}$ Department of Otorhinolaryngology, Juntendo University of Medicine, Faculty of Medicine, Japan

\begin{abstract}
Concerning tonque-base cysts, infant cases with emergency symptoms such as dyspnea and choking have been reported. However, adult cases are quite rare. We experienced a 40-year-old man with a huge tongue-base cyst. In spite of the resulting severe, middle pharyngeal stenosis, his chief complaint was only slight throat discomfort without dyspnea. We performed pharyngo-laryngo-microsurgery using an oral approach. The throat discomfort disappeared after the operation. Histopathologic examination showed squamous epithelia in cyst lumens and many mucous glands in the sub-epithelial layer without thyroid tissue. The content of tongue-base was mucus. The above findings suggested that our case may represent a cyst arising from mucous gland.
\end{abstract}

\section{Introduction}

Tongue-base cysts are benign lesions. Infant cases with dyspnea and feeding difficulty have been reported [1,2]. However, adult cases are extremely rare [3]. We experienced an adult case of a tongue base cyst that nearly occupied the pharyngeal space. This case report presents the clinical findings, imaging examination, operation and histopathological examination. Moreover, we discuss the cause of the tongue base cyst based on the operative and histopathological findings and with reference to various studies.

\section{Case presentation}

We experienced a 40-year-old man who came to our hospital with a 4-month history of throat discomfort without dyspnea or dysphagia as his chief complaint. In the initial findings, laryngoscope could find a huge cyst in the midline position at the base of the tongue. Since this huge tongue-base cyst almost occupied the pharyngeal lumen,the epiglottis and vallecula epiglottica bellow the cyst could not be visualized (Figure 1). In spite of the severe, middle pharyngeal stenosis, the chief complaint was only throat discomfort without dyspnea or dysphagia. Magnetic resonance imaging (MRI) revealed a homogenic

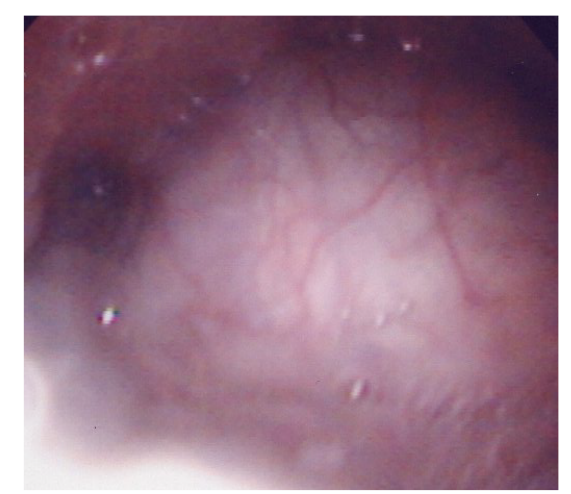

Figure 1. In the laryngoscopic findings, since the huge tongue-base cyst almost completely occupied the pharyngeal lumen, the epiglottis and valleculaepiglottica below the cyst could not be observed. and well-defined cystic mass with low intensity on T1 weight and high intensity on T2 weight (Figure2). We performed pharyngo-laryngomicrosurgery. At first, the volume of the cyst was decreased by incising a part of the perimeter of the cyst and we could remove majority of the cyst.

This procedure enabled confirmation of the relationships among the epiglottis, vallecula epiglottica allowing safe resection of the cyst. The liquid component of the cyst was brown mucous. Histopathologic examination revealed squamous epithelia in cyst lumens and many mucous glands in the sub-epithelial layer without malignant cells or thyroid tissue (Figure 3). The throat discomfort disappeared after surgery.

Postoperative laryngoscopic examination could confirm the absence of airway stenosis (Figure 4).

\section{Discussion}

Reports of tongue-base cysts have generally been infant cases with emergency symptoms such as dyspnea and choking, while adult case reports have been few. Sugita [3] reported an adult case with a huge

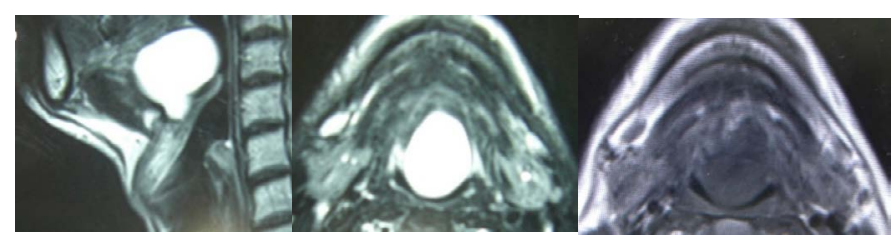

Figure 2. In MRI, a homogenic and well-defined cystic mass was high intensity on T2 weight (right, middle) and low intensity on $\mathrm{T} 1$ weight (left).

Correspondence to: Dr. Takeshi Kusunoki, Department of Otorhinolaryngology, Juntendo University of Medicine, Shizuoka Hospital, 1129 NagaokaIzunokunishi, Shizuoka 410-2295, Japan; Fax: +81-55-948-5088; E-mail:ttkusunoki001@aol.com

Key words: tongue base mucocele, adult, thyroglossal duct cyst

Received: November 19, 2016; Accepted: December 19, 2016; Published: December 23, 2016 


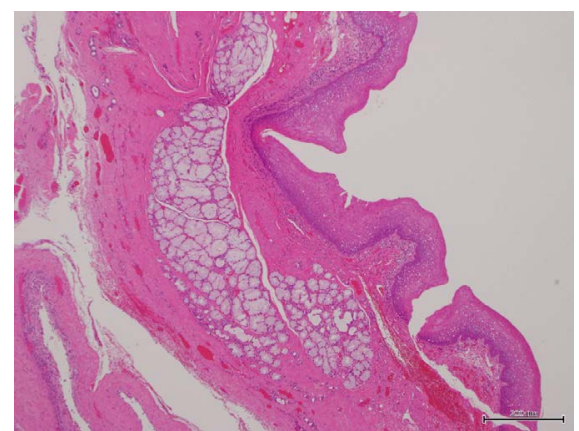

Figure 3. Histopathologic examination (HE staining) revealed squamous epithelia in cyst lumens and many mucous glands in the sub-epithelial layer but not thyroid tissue.

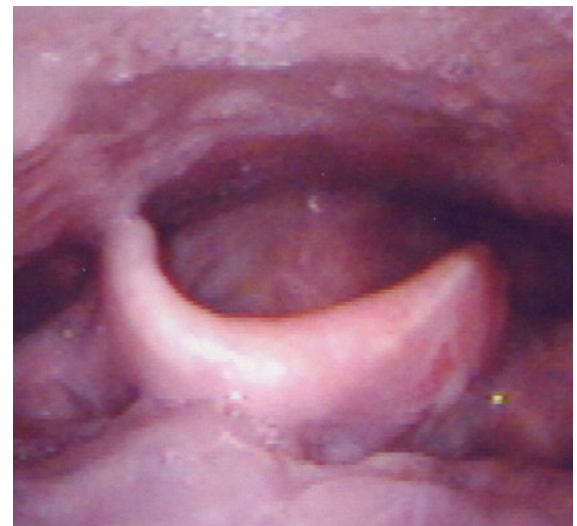

Figure 4. Postoperative laryngosopic examination confirmed the absence of airway stenosis.

tongue-base cyst and the chief complaint was only dysphonia without dyspnea or dysphagia. The chief complaint of our adult case was also a slight throat discomfort without dyspnea or dysphagia. However, there are structural differences in the airway between adult and infant, as follow. The airway lumen is narrow and the supporting tissues are soft in infant. Therefore, infants more easily fall into dyspnea with even a slight stenosis of the airway [4]. In contrast, adult cases of a tongue-base cyst rarely showed emergency symptoms such as dyspnea. Therefore, it is possible that adult cases have not been fully described [3].

Some reporters considering some possible causes of tongue-base cysts suggested they might arise from thyro-glossal ducts or mucous glands [5-7]. The various locations of thyroglossal duct cysts have been classified as intralingual, suprahyoid, infrahyoid(thyrohyoid), and suprasternal [8]. Hur [6] described that differential diagnoses of a tongue-based mucocele should include cystic lesions of the tongue such as the intralingual type of thyroglossal duct cyst. Actually, the distinction is between a tongue-base mucocele and an intralingual type of thyroglossal duct cyst $[6,7]$. Preoperatively, we also suspected a tongue-base mucocele or intralingual type of thyroglossal duct cyst. Because,our tongue-base mucocele located in the midline position at the base of the tongue like as intralingual type of thyroglossal duct cyst. Radiological scanare difficult to distinguish these two cysts [6]. Our histopathologic examination showed squamous epithelia in the cyst lumenand many mucous glands in the sub-epithelial layer without thyroid tissues. The content of the tongue-base was mucus. From the above findings, in our case the cyst may have arisen from mucus gland.

\section{Declarations}

\section{Author's contributions}

Takeshi Kusunoki MD : Diagnosis and therapy, composition of this case report

$\begin{array}{ll}\text { HirotomoHonma MD } & \text { : Therapy } \\ \text { YoshinobuKidokoro MD } & \text { : Therapy } \\ \text { AyaYanai MD } & \text { : Therapy } \\ \text { Ryo Wada MD } & \text { : Pathological diagnosis } \\ \text { Katsuhisa Ikeda MD } & \text { : Composition of this case report }\end{array}$

Consent for publication:We confirmed a patient's anonymity and consent for publication on pathological examinationwas obtained for this case report.A copy of this document is available for review by the Editor of this journal.

Acknowledgements: The authors thank Mr.Brent Bell for checking English of the manuscript.

Competing interests: The authors have no conflict of interest to disclose.

\section{References}

1. Wenglowski R (1912) Uber die Halsfisteln und Cysten. Arch f Klin Chir 98: 151-208.

2. LaBagnara J Jr (1989) Cysts of the base of the tongue in infants: an unusual cause of neonatal airway obstruction. Otolaryngol Head Neck Surg 101: 108-111. [Crossref]

3. Sugita K, Oda M (1981) A case report of huge cyst of the base of the tongue. Otolaryngology 53: 581-585.

4. Kumanomidou H, Kawashiro N, Tsuchihashi N, Shishiyama F (1997) Tongue base cysts in infants. Stomato-Paryngology 9: 393-401.

5. Shapiro MJ (1949) Cysts on the base of the tongue in infants. Ann Otol Rhinol Laryngol 58: 457-469. [Crossref]

6. Hur JH, Byun JS, Kim JK, Lee WJ, Lee TJ, et al. (2016) Mucocele in the Base of the Tongue Mimicking a Thyroglossal Duct Cyst: A Very Rare Location. Iran J Radiol 13: e24827. [Crossref]

7. Sato Y (1982) A successful operation for pharyngeal cyst in a newborn girl. Japanese Journal of Pediatric Surgery 14: 263-267.

8. Montgomery WW (1989) Surgery of the upper respiratory system. Vol 2.In: Thyrogossal duct and lingual thyroid. 2th ed.Phiadelphia: Lea\&febiger 150-153.

Copyright: (C2016 Kusunoki T. This is an open-access article distributed under the terms of the Creative Commons Attribution License, which permits unrestricted use, distribution, and reproduction in any medium, provided the original author and source are credited. 